\title{
PRELIMINARY WORK DOMAIN ANALYSIS FOR HUMAN EXTRAVEHICULAR ACTIVITY
}

\author{
Type name and affiliation information here ONLY FOR FINAL PUBLICATION DRAFT \\ (do not include names/affiliations for first submission, to preserve blind review) \\ Coauthor information can be on separate lines
}

\begin{abstract}
A work domain analysis (WDA) of human extravehicular activity (EVA) is presented in this study. A formative methodology such as Cognitive Work Analysis (CWA) offers a new perspective to the knowledge gained from the past 50 years of living and working in space for the development of future EVA support systems. EVA is a vital component of human spaceflight and provides a case study example of applying a work domain analysis (WDA) to a complex sociotechnical system. The WDA presented here illustrates how the physical characteristics of the environment, hardware, and life support systems of the domain guide the potential avenues and functional needs of future EVA decision support system development.
\end{abstract}

\section{MOTIVATION}

Human spaceflight is arguably one of mankind's most challenging engineering feats, requiring carefully crafted synergy between human and technological capabilities. One particular component of human spaceflight pertains to the activities conducted outside the safe confines of the spacecraft, known as extravehicular activity (EVA). The past five decades of human spaceflight have established EVA as a mission critical capability necessary for spacecraft and payload inspection, repair, and construction (Portree \& Treviño, 1997). The successful execution of EVA requires significant effort undertaken by astronauts and the personnel that support all aspects of EVA from the ground. These support personnel are known as EVA flight controllers and they strive to manage the flight crew, the EVA timeline, and all associated hardware. They oversee all planning activities prior to, during, and after an EVA and support off-nominal events such as hardware malfunctions, unscheduled task difficulties, and crew health variations. (See Miller et al., (2015) for a summary of current EVA operations). EVA typifies the definition of a complex sociotechnical system. Communication plays a vital role between the many specialized EVA personnel who operate in a distributed, dynamic, uncertain environment.

NASA has ambitions of sending humans beyond Low Earth Orbit (LEO), which will impose a host of technological challenges. Once such challenge is over coming asynchronous communication, as there will be an appreciable delay in the messages sent between ground personnel and crew (on the order of 4 to 20 minutes for one way communications between Earth and Mars). The limited, yet growing, body of literature has just begun to address asynchronous communication in a variety of ways such as developing real-time schedule replanning (Marquez, Ludowise, McCurdy, \& Li, 2010) and subsystem automation (Stetson, Deitsch, Cruzen, \& Haddock, 2007; Stetson, Knickerbocker, Cruzen, \& Haddock, 2011). There has also been efforts to enhance astronaut capability via prototype cuff display (Carr, Schwartz, \& Rosenberg, 2002; Hodgson et al., 2003) and helmet display development (Jacobs, Di Capua, Husain, Mirvis, \& Akin, 2011; Stolen, Dillow, Jacobs, \& Akin, 2008). Various other software advances have also been developed recently including prototype automated timeline tracking, activity scheduling, and fault-detection (See Smith et al., (2014) for a summary). However, there has been limited research utilizing a formative framework to inform decision support system (DSS) design for EVA (Marquez, 2007).

The purpose of this study is to provide a formative framework to define both the operational and physical constraints that exist within the EVA work domain using abstraction hierarchies. Intentional, or social, constraints that exist within the EVA work domain were not considered for this study. This work builds off of previous work conducted by Miller et al., (2015) that identified and examined current EVA support operations.

\section{Analytical Method}

The data used for this research originates from a variety of sources as shown in Table 1. These data sources were chosen based on their accessibility and intimate association to the EVA work domain for preliminary abstraction hierarchy (AH) construction (Naikar et al., 2005; Vicente, 1999). The method used in this study follows the WDA approach as outlined by Naikar et al., (2005), which incorporates a ninestep process. This paper serves as a preliminary study, which utilized only the first six steps to construct the abstraction hierarchies due to time and resource constraints. Atlas.ti $7^{\circ}$ was used as the primary resource manager, enabling the rapid construction and alteration of abstraction hierarchies.

\section{EVA WORK DOMAIN REPRESENTATION}

As specified in the first step of WDA development, the overall purpose of the EVA WDA was to identify the objectives of the EVA work system and link those objectives to the technical and engineered resources and processes involved in achieving those objectives. Previous work has already investigated the key personnel and their respective roles and responsibilities involved in EVA operations to provide some overall context of the current EVA work domain (Miller et al., 2015). This paper builds upon that work by modeling the work domain as a set of abstraction hierarchies (Vicente, 1999). 
Table 1. Data collection for EVA work domain analysis.

\begin{tabular}{ll|l}
\hline Data Source & Description & Data Collection \\
\hline \hline $\begin{array}{l}\text { NASA Console Handbooks, NASA } \\
\text { Technical Reports, published literature }\end{array}$ & $\begin{array}{l}\text { Review of operational procedures, processes, and flight } \\
\text { rules; Review of previous EVA studies }\end{array}$ & $\begin{array}{l}\text { Reviewed operational aspects related to EVA including roles } \\
\text { and responsibilities of personnel involved in EVA support }\end{array}$ \\
\hline $\begin{array}{l}\text { Semi-structured interviews with EVA } \\
\text { personnel }\end{array}$ & Interviews with SMEs about the EVA work domain & $\begin{array}{l}\text { 4 domain experts interviewed regarding operational aspects } \\
\text { of the EVA work domain }\end{array}$ \\
\hline $\begin{array}{l}\text { Observations of archived EVA flight } \\
\text { audio/video footage }\end{array}$ & $\begin{array}{l}\text { Observed EV crew operate within the work domain and } \\
\text { the communication interactions with Mission Control }\end{array}$ & $\begin{array}{l}4 \text { EVAs (2 nominal 2 off-nominal) audio/video files were } \\
\text { observed ( 26 hours of footage })\end{array}$ \\
\hline
\end{tabular}

\section{Definition of the EVA WDA boundary}

The first step in $\mathrm{AH}$ construction was to define the boundary of the system to be analyzed. The EVA work domain can be bounded by two considerations: 1) the current organizational structure that exists within the work domain, and 2) the elements of life support required to sustain human survival. Without the protection provided by engineered systems, EVA would not be possible. Figure 1 shows the EVA work domain boundary objects considered in this study.

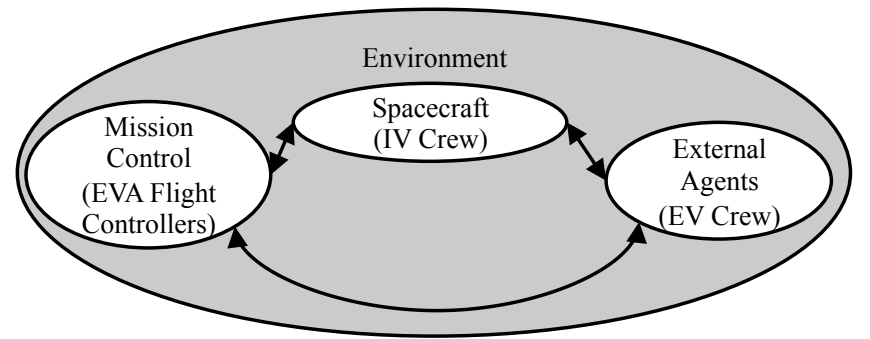

Figure 1. EVA work domain boundary objects

The boundaries of the EVA work domain can be decomposed into four elements, that when considered together, enable the work within the EVA work domain to be performed. Known as extravehicular (EV) crew, the human external agents are located exterior of their spacecraft and are bounded by their spacesuit. The hull of the spacecraft bounds the operators within the spacecraft, who are known as intravehicular (IV) crew. Finally, the EVA work domain includes Mission Control, located at NASA Johnson Spaceflight Center, in Houston, Texas. Within Mission Control, a subset of personnel are dedicated to EVA support (Miller et al., 2015). The work environment spans all three boundary objects and influences the capability of work performed by each boundary object within the work system. Viewing the EVA work domain from this perspective enables the integration of various stakeholder perspectives and a discussion of interactions within and between boundary objects at all levels of abstraction (Burns, Bryant, \& Chalmers, 2005).

\section{Preliminary abstraction hierarchy construction}

Table 2 shows a preliminary EVA abstraction hierarchy. Given the complex, distributed operations involved with performing an EVA, this study is concerned with functions and constraints present during the actual execution of an EVA, as opposed to incorporating all the preparatory and post-EVA operations. In general, there is a common goal or set of objectives among all members of the work domain. The models presented in this paper are intended to describe the affordances and constraints in the work environment that influence the overall execution of EVA objectives rather than any single objective. The environment $\mathrm{AH}$ is discussed without a functional purpose, but rather as a boundary that adheres to the physical laws of nature. At the level of abstract function, the EVA work domain is highly constrained by the management processes of mass, energy and resource information. Human rated space equipment operates with tight operational margins, which makes all sources of consumables, energy, and mass valuable. The physical constraints displayed at the physical function and physical form levels indicate a strong causal relationship that exists between the EVA boundary objects.

\section{Expanded abstraction hierarchy construction}

Figures 2 and 3 show the expanded abstraction hierarches where the EVA work domain's purposes and constraints are delineated. Figure 2 shows the overarching EVA purposes and constraints overlaid with the associated boundary objects for present day EVA operations. The abstraction levels shown in Figure 2 are meant to highlight the current operational ownership over each level of abstraction. Each level is discussed in the following sections.

Table 2. Summarized abstraction hierarchy for human EVA.

\begin{tabular}{|c|c|c|c|c|}
\hline Level of Abstraction & $\begin{array}{c}\text { Mission Control } \\
\text { (EVA Flight Controllers) }\end{array}$ & $\begin{array}{l}\text { Spacecraft } \\
\text { (IV Crew) }\end{array}$ & $\begin{array}{c}\text { External Agent } \\
\text { (EV crew) }\end{array}$ & Environment \\
\hline Functional Purpose & \multicolumn{3}{|c|}{ Ensure mission success (achieve objectives and maintain crew safety) } & \\
\hline Abstract Function & \multicolumn{3}{|c|}{ Flow and balance of mass, energy, and resources information } & $\begin{array}{l}\text { Flow and balance of mass, energy, } \\
\text { creation of entropy }\end{array}$ \\
\hline $\begin{array}{l}\text { Generalized } \\
\text { Function }\end{array}$ & $\begin{array}{l}\text { Processes of coordination, } \\
\text { supervisory control, resource } \\
\text { management, anomaly } \\
\text { response \& resolution, } \\
\text { guidance }\end{array}$ & $\begin{array}{l}\text { Processes of coordination, } \\
\text { translation, resource } \\
\text { management, anomaly } \\
\text { response \& resolution } \\
\text { guidance }\end{array}$ & $\begin{array}{l}\text { Processes of coordination, } \\
\text { translating, stabilization, tools } \\
\text { and hardware handling, } \\
\text { worksite management, mass } \\
\text { handling }\end{array}$ & $\begin{array}{l}\text { Atmospheric, solar, electromagnetic } \\
\text { processes }\end{array}$ \\
\hline Physical Function & \multicolumn{3}{|c|}{ Capabilities of human, tools, and hardware } & $\begin{array}{l}\text { Capabilities of atmosphere, radiation, } \\
\text { terrain properties to permit activities }\end{array}$ \\
\hline Physical Form & \multicolumn{3}{|c|}{ Physical location, conditions, shape, size of hardware } & $\begin{array}{l}\text { Physical location in space, } \\
\text { atmospheric, radiation, terrain } \\
\text { conditions }\end{array}$ \\
\hline
\end{tabular}




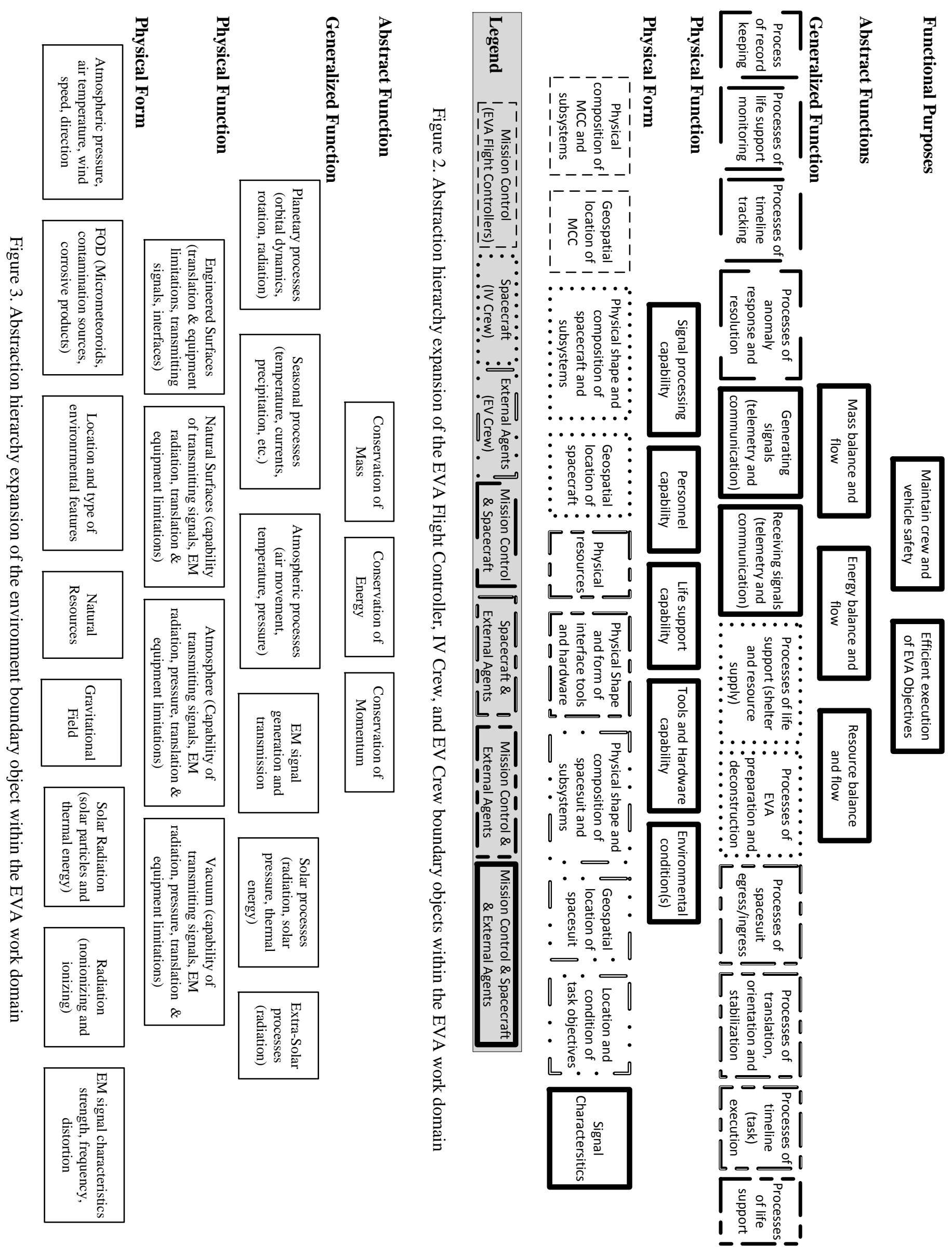




\section{Functional Purpose.}

An EVA is performed with a clear goal or set of objectives that define the EVA purpose, whether it is a maintenance repair task or scientific activity. Additionally, the competing goal of maintaining crew and vehicle safety is ever present. The more risky the objective(s), the higher the risk incurred by the crew member(s). Crew safety is the predominant priority during an EVA and no objective is entertained without considering the associated ramifications to crew safety. A DSS designed to assess crew safety and EVA timeline planning would increase crew capacity to perform EVA real-time planning and anomaly response.

\section{Abstract Function.}

The safety and objective priorities are measured by the efficient use of available mass, energy, and resource information. These constraints are physical in the sense that every system at the disposal of the crew has specific design criteria and operational envelopes. Each activity conducted during EVA can be traced to the constraints imposed by the finite mass, energy, and resources. All boundary objects must consider these priority criteria in order to achieve the EVA functional purposes. Current EVA operations heavily leverage Mission Control capabilities for managing these criteria. EVA is one component of the larger mission architecture that utilizes common resources. A DSS that could synthesize state information would help prevent the crew from exceeding safe system operational envelopes.

\section{Generalized Function.}

Many of the constraints at the generalized function level derive from concerns associated with generating, receiving, and processing signals. In their raw form, these signals include both the raw telemetry data of tools and hardware as well as the audio/video/text information. The exchange of this information is a critical constraint to effective objective execution while maintaining crew safety. The distributed nature of the EVA work domain also lends itself to the unique perspective that domain knowledge is not always concentrated locally where the work is being performed. Mission Controllers provide the critical functions of supervisory control and anomaly response and resolution. These functions are especially important as it pertains to EVA timeline management and life support system monitoring. The fusion of raw life support data with timeline management systems is another potential avenue for DSS implementation.

\section{Physical Function.}

The physical function level describes the functional capabilities of the individual spacesuit, spacecraft, tools, and hardware. Currently, limited diagnosis and anomaly response capabilities exist for the crew and Mission Control is relied upon to monitoring these functional capabilities. Constraints for the EVA domain also include the personnel capabilities of the astronauts themselves, both in terms of physical endurance as well as mental and workload capacities. Internal environmental constraints such as a crew comfort and hardware access also impact EVA operations, especially for IV and EV crewmembers.

\section{Physical Form.}

At the physical form level, constraints are derived from the geographical distribution of assets, resources, and signal characteristics. Physical constraints are also present in the form of hardware interactions between the external agents and the spacecraft (i.e. spacesuit and airlock interfaces). The characteristics of the signals transferred are the only forms of interactions that extend to all EVA operators within the domain. The opportunity for EV and IV crew to interact also exists at the physical form level through hardware interfaces that exist between the spacecraft and spacesuit/hardware. Management and presentation of communicated information using a DSS has the potential to ease the burden of information overload on the crew.

\section{EVA environment expansion}

The EVA environment was modeled similar to (Burns et al., 2005) in that the functional purpose level was not included. The following discussion includes the remaining four abstraction levels.

\section{Abstract Function.}

The measures by which the environment operates follow the forces of nature in the forms of the conservation equations (i.e. conservation of mass, momentum, and energy).

\section{Generalized Function.}

The generalized function level is divided into physical processes that are associated with various environment regions of EVA operations. These include planetary processes such as orbital mechanics as well as solar processes. Whether in the vacuum of space or on a planetary surface, the EVA work domain is strongly influenced by the presence of electromagnetic (EM) radiation both from a crew health standpoint and a signal transmission perspective.

\section{Physical Function.}

The elements included in the physical function level pertain to the operational environments of the external agents. Once beyond LEO, solar and extra-solar processes become strong physical constraints on crew health and signal transmission capabilities. Earth atmospheric processes also impact Mission Control's ability to communicate with the crew. EV crewmembers must physically interact with their environment, which in some cases can be engineered, or manmade, surfaces such as the International Space Station or natural surfaces like the surface of Mars. Each type of surface constrains translation, communication coverage, and hardware capabilities.

\section{Physical Form.}

At physical form level, the model delineates elements that are pertinent for EVA operators to collect and monitor. Elements such as terrain layout, radiation levels, and foreign objects and debris (FOD) are just a few of the environmental measures that are useful to EVA operators. 


\section{DISCUSION}

The potential avenues for decision support system design within the EVA work domain can be concentrated in two parts: between object support and within object support. As shown in Figure 2, the processes of signal generation, transfer and receiving between boundary objects are shown as a critical aspect of EVA operations. However, the operational distribution of work shown in Figure 2 is for present day operations. Future EVA operations are not necessarily beholden to a Mission Control centric strategy, but the elements displayed in Figures 2 and 3 will still remain. Processes such as life support monitoring, timeline tracking, and anomaly response and resolution will still exist. The IV and EV crew will need a support system that can assist them locally in ensuring all of these physical constraints are met.

Within boundary objects support system design offers another promising avenue for development, specifically within the spacecraft boundary object. A fundamental trade-off exists at the functional purpose level where EVA objectives are against the safety of the crew. The exact EVA objective may vary, however, maintaining crew safety remains constant. Crew life support is linked to the physical hardware and resource capabilities that exist locally with the IV and EV crewmembers. The IV crewmember has the unique placement within the work domain to not only monitor in the physical resources locally; they also have the infrastructure (i.e. the spacecraft) to interact with Mission Control. Furthermore, the importance of the IV crewmember has already been emphasized as a critical operational component of future EVA operational concepts (Abercromby, Chappell, \& Gernhardt, 2013). Designing a support system specifically for the IV crewmember has the potential to enable the crew to locally monitor life support systems and EVA timeline information as well as integrate that information with Mission Control input for anomaly response and resolution. While it is true that future EVA life support hardware capabilities will likely be more advanced than present day, the fact that these systems must be closely supervised and integrated with real-time EVA decision making activities will remain, especially for time critical situations where crew safety is threatened. Additionally, the support system will need to account for constraints derived from the EVA environment model.

\section{CONCLUSION}

The elements of abstraction shown in Figures 2 and 3 offer a preliminary attempt at isolating the physical, operational, and environmental constraints that exists within the EVA work domain. The decomposition of the EVA work domain into boundary objects enabled the integration of the various boundary objects' perspectives. The critical relationship between EVA life support capability and timeline execution was identified. EVA environmental constraints were also modeled to extract the imposing limitations the environment also has on EVA operation. Providing the local crew with the support systems necessary to synthesize, and act on information derived from their physical systems and environment will play a critical role in the successful execution of future EVA.

\section{ACKNOWLEDGEMENTS}

This research was sponsored by the NASA Space Technology Research Fellowship - Grant \# NNX13AL32H. The authors would like to thank all those from the NASA community who participated in meetings and interviews as well as the reviewers for their guidance in the revisions of this manuscript. The opinions expressed in this study are of the authors alone and are not reflective of NASA.

\section{REFERENCES}

Abercromby, A. F., Chappell, S. P., \& Gernhardt, M. L. (2013). Desert Rats 2011: Human And Robotic Exploration Of Near-Earth Asteroids. Acta Astronautica, (91), 34-48.

Burns, C. M., Bryant, D. J., \& Chalmers, B. A. (2005). Boundary, Purpose, and Values in Work-Domain Models: Models of Naval Command and Control. Systems, Man and Cybernetics, Part a: Systems and Humans, IEEE Transactions on, 35(5), 603-616. doi:10.1109/TSMCA.2005.851153

Carr, C. E., Schwartz, S. J., \& Rosenberg, I. (2002). A wearable computer for support of astronaut extravehicular activity, 23-30.

Hodgson, E., Sidgreaves, R., Braham, S., Hoffman, J., Carr, C., Lee, P., et al. (2003). Requirements and potential for enhanced EVA information interfaces. Presented at the 33rd International Conference on Environmental Systems (ICES), Vancouver, B.C., Canada: SAE Technical Paper.

Jacobs, S. E., Di Capua, M., Husain, S.-A. A., Mirvis, A., \& Akin, D. L. (2011). Incoporating Advanced Controls, Displays and other Smart Elements into Space Suit Design. SAE Int. J. of Aerosp., 4(1), 374-384.

Marquez, J. J. (2007, February). Human-Automation Collaboration: Decision Support for Lunar and Planetary Exploration. (M. L. Cummings). $\mathrm{PhD}$ Thesis - MIT.

Marquez, J., Ludowise, M., McCurdy, M., \& Li, J. (2010). Evolving from Planning and Scheduling to Real-Time Operations Support: Design Challenges. Presented at the 40th International Conference on Environmental Systems, American Institute of Aeronautics and Astronautics. doi:10.2514/6.2010-6282

Miller, M. J., McGuire, K. M., \& Feigh, K. M. (2015). Information Flow Model of Human Extravehicular Activity. Presented at the IEEE Aerospace Conference, Big Sky, MT.

Naikar, N., Hopcroft, R., \& Moylan, A. (2005). Work domain analysis: Theoretical concepts and methodology (No. TR-1665). Air Operations Division DSTO Defence Science and Technology Organisation. Fishermans Bend, Australia: Air Operations Division.

Portree, D. S. F., \& Treviño, R. C. (1997). Walking to Olympus : an EVA chronology. Washington, DC : NASA History Office, Office of Policy and Plans, NASA Headquarters.

Smith, E. E., Korsmeyer, D. J., \& Hall, V. (2014). Exploration Technologies for Operations. Presented at the 13th International Conference on Space Operations 2014, Pasadena, CA: American Institute of Aeronautics and Astronautics. doi:10.2514/6.2014-1619

Stetson, H. K., Deitsch, D. K., Cruzen, C. A., \& Haddock, A. T. (2007). Autonomous payload operations onboard the international space station (pp. 1-12). Presented at the IEEE Aerospace Conference, IEEE.

Stetson, H. K., Knickerbocker, G., Cruzen, C. A., \& Haddock, A. T. (2011). The HAL 9000 Space Operating System (pp. 1-24). Presented at the IEEE Aerospace Conference. doi:10.1109/AERO.2011.5747602

Stolen, M. F., Dillow, B., Jacobs, S. E., \& Akin, D. L. (2008). Interface for EVA Human-Machine Interaction. Presented at the 38th International Conference on Environmental Systems, San Francisco, CA: SAE Technical Paper.

Vicente, K. (1999). Cognitive Work Analysis : Toward Safe, Productive, and Healthy Computer-based Work. Mahwah, N.J.: Lawrence Erlbaum Associates. 